\title{
Review on Pregnancy Toxemia in Sheep with Observation of Resolution Using ReaShure (Protected Choline)
}

\author{
Osman A. Hameed* \\ Central Veterinary Laboratory, Khartoum, Sudan \\ ^Corresponding author: Osman A Hameed, Central Veterinary Laboratory, Khartoum, Sudan; E-mail: osmanhs@yahoo.com
}

Received: April 13, 2021; Accepted: April 27, 2021; Published: April 29, 2021

Pregnancy toxemia is a metabolic disorder in sheep and goats which usually develops during late gestation and which is always associated with hyperketonemia and hypoglycemia. Ewes of certain breeds, mainly when bearing two or three lambs, are more susceptible than ewes only one fetus [1]. The economic significance of the disease is determined by reduced milk yields and body weight loss, poor feed conversion, increased culling and mortality rates of offspring and affected animals [2].

Compared to dry ewes, ewes in late pregnancy require about 50 percent more feed if bearing a single lamb and about 75 percent more feed if carrying twins. This amount of feed may exceed their intake capacity unless grain is substituted for part of the ration [3]. Ovine pregnancy toxemia or "twin-lamb" disease occurs in the latter part of pregnancy in sheep, typically in ewes with multiple fetuses, and is characterized by anorexia and neurologic signs of motor weakness, amaurosis, and mental dullness. It may occur spontaneously or may be induced by dietary deficiency. The disease is associated with the high calorific requirements of pregnant sheep.

Pregnancy toxemia may occur following a relative deficiency of available carbohydrate that leads to a drain on oxaloacetate and its precursors in an effort to maintain blood glucose concentration. Toxemia can usually be prevented by adequate supplementary feeding in late pregnancy. Clinical pathologic studies show consistent elevation of blood ketones and glucocorticoids and, in the early part of the disease, decreased blood glucose. Subclinical ketosis is defined as elevated concentration of circulating ketone bodies in the absence of clinical signs [4]

There are four categories of disease according to [5]: 1) Primary pregnancy toxemia caused by inadequate nutrition (poor quality feed, period of fasting) 2) Fat ewe/doe pregnancy toxemia seen in overconditioned ewes/does in early gestation (suffer a nutritional decline in late gestation, possibly from smaller rumen capacity) 3) Starvation pregnancy toxemia seen in severely under-conditioned ewes/does (lack of feed after drought, heavy snow or flood) and 4) Secondary pregnancy toxemia due to concurrent disease such as parasites, poor dentition, or lameness.

Hyperketonaemia is defined as an abnormally high concentration of circulating ketone bodies during the postpartum period. The gold standard diagnostic test for Hyperketonaemia is the test for hyperketonaemia is the measurement of hydroxybutyric acid (BHBA) in serum or plasma by a laboratory process [6]. The most commonly used level of serum BHB to identify ketosis is a concentration $\geq 1400$ $\mathrm{mol} / \mathrm{l}(14.4 \mathrm{mg} / \mathrm{dl})$ [7].

An alternative to the laboratory method is blood BHBA measurement that can be used as on - farm cow side test for hyperketonaemia with a near perfect accuracy (Precision Xtra; sensitivity $96 \%$, specificity $97 \%$ ). More recently, cow side tests for ketosis have focused on measuring BHBA level. One test is Keto Test (Sanwa Kagaku Kenkyusho Co Ltd, Nagoya, Japan; distributed by ELANCO Animal Health, Greenfield, IN). This test measures BHBA in milk and consists of test strips on which a reagent converts BHBA in the milk sample to AcAc. Using a provided colour scale, the strip may be used to semi-quantitatively measure BHBA concentration $\mathrm{s}$ in the milk sample based on intensity of the colour change observed on test strip [8,9]. A new blood strip test for BHBA and glucose was developed and manufactured by DFI CO., Ltd (South Korea). Recently a new test BHBCheck Plus (blood ketone \& glucose test system) manufactured by PortaCheck, Inc, USA. Laboratory findings in individual animals may include hypoglycemia (often $<2 \mathrm{mmol} / \mathrm{L}$ ), elevated urine ketone levels, elevated BHBA levels (normal $<0.8 \mathrm{mmol} \mathrm{L}$, subclinical ketosis $>0.8 \mathrm{mmol} \mathrm{L}$ and clinical disease $>3.0 \mathrm{mmol} / \mathrm{L}$ ) and frequently hypocalcemia and hyperkalemia due to severe ketoacidosis [10].

Blood glucose concentration between 40 and $65 \mathrm{mg} / \mathrm{dl}$ are common in pregnancy toxemia, although comatose animals may show terminal hyperglycemia, especially associated with fetal death [11]. To prevent ketosis in sheep, goats, it is important to identify the animals carrying twins or triple, separate them and provide them with a diet that will meet their energy demand. Successful treatment of pregnancy toxemia requires early detection and steps to quickly meet the energy (glucose) needs of the affected ewe. The most common treatment is to drench ewes with 2 to 3 ounces of propylene glycol 2 to 3 times daily. Propylene glycol, which is mainly absorbed intact directly from the rumen at a rate of $40 \%$ per hour and reaches its maximum blood level within $30 \mathrm{~min}$ of administration and maximum blood glucose conversion at about $4 \mathrm{~h}$ after administration. Propylene glycol transformation in glucose probably occurs via conversion to pyruvate [12]. 
Reashure microencapsulated choline, a recent technological breakthrough, protects choline on its journey rough-and -tumble rumen and releases it in the small intestine. Lipid (fat) layers, applied using a proprietary process, encapsulate (coat) the choline. At the time of calving and during negative energy balance, feeding ReaShure increases fat export out of the liver which prevents fatty liver and reduces the amount of fatty acids converted to ketones by the liver $[13,14]$.

Feeding ReaShure also reduced the incidence of mastitis $(\mathrm{P}=0.06)$ and all postpartum diseases combined $(\mathrm{P}=0.001)$. Clearly, cows fed ReaShure were healthier and produced more milk [15]. The impact of feeding of ReaShure to sheep is obvious in reducing the incidence of ketosis in sheep (pregnancy toxemia). Sheep fed ReaShure are healthier compared to those not fed Rea Shure. Also, it reduced the incidence of abortion [16].

Keywords: Pregnancy toxaemia-Ketosis Beta-hydroxybutyrate (BHB)-, Hypoglycemic-hyperglycemic-hyperketonemia-propylene glycol-protected choline (ReaShure)-acetone or acetoacetate (AcAc), BHB check plus (blood ketone \& glucose test system), Qucare Vet Meter - Qucare Vet strips - mmol/l-Subclinical Ketosis-Abortion

\section{References}

1. Harmeyer J, Schlumbohm C (2006) Pregnancy impairs ketone body disposal in late gestating ewes: Implications for onset of pregnancy toxemia. Research in Veterinary Science 81: 254-264. [crossref]

2. Caldeira RM, Belo AT, Santos CC, Vazques MI, Portugal AV (2007) The effect of body condition score on blood metabolites and hormonal profiles i ewes. Small Rumin Res 68: 233-241

3. James M Sachse (1996) Extension Sheep Specialist. American Sheep Industry Association Inc, Production Education, and Research Council.

4. ANDERSSON L (1988) Subclinical ketosis in dairy cows. Vet Clin N Am Food Anim Pract 4: 233-251. [crossref]
5. Edmondson MA, Roberts JF, Baird AN, Bychawski S, and Pugh DG (2012) Theriogenology of Sheep and Goats. In: Pugh DG, Baird AN, eds. Sheep and Goat Medicine, 2nd Edition. Maryland Heights, MO: Elsevier-Saunders 150-231.

6. Tyopponen J, Kauppinen K (1980) The stability and automatic determination of ketone bodies in blood samples taken in field condition. Acta Vet Scand 21: 55-61. [crossref]

7. Oetzel GR (2004) Monitoring and testing dairy herd for metabolic disease. Vet Clin North Am 20: 651-674. [crossref]

8. Geishauser T, Leslie K, Tenhag J, Bashiri A (2000) Evaluation of eight cow Side Ketone tests in milk for detection of subclinical Ketone tests in milk for Detection of subclinical Ketosis in dairy cows. J Dairy Science 83: 296-299. [crossref]

9. Carrier J, Stewart S, Godden S, Fetrow J, Rapnicki P (2004) Evaluation and use of three cowside tests for detection of subclinical ketosis in early postpartum postpartum cows. Dairy Sci 87: 3725-3735. [crossref]

10. Ramin AG, Asri-Rezaie S, Macali SA (2007) Evaluation on serum glucose, BHB, urea and cortisol in pregnant ewes. Medycyna Wet 63: 674-677.

11. Marteniuk JW, Herdt TH (1988) Pregnancy toxemia and ketosis of ewes and does. Vet din North Am Food Anim Pract 4: 307-315. [crossref]

12. Herdt TH, Emery RS (1992) Therapy of diseases of ruminant intermediary metabolism. Vet Clin North Am Food Anim Pract 8: 91-106. [crossref]

13. Cooke RF, Del Rio NS, Caraviello DZ, Bertics SJ, Ramos MH, et al. (2007) Supplemental choline for prevention and alleviation of fatty live in dairy cattle. $J$ Dairy Sci 90: 2413-2418. [crossref]

14. Zom R, Baal J van, de Veth MJ, Goselink RMA, Widjaja- Greefkes HCA, et al. (2010) Effect of rumen -protected Choline on performance and hepatic fat metabolism in periparturient dairy cattle and hepatic fat metabolism in periparturient. J Dairy Sci 93: 781

15. Santos JP, Lima FS (2009) Feeding rumen-protected choline to transition dairy cows. Page 149 in Proceedings of the Florida Ruminant Nutrition. Univ.Florida, Gainesville.

16. Hameid OA, Abu-Zeid TESA, Mustafa Taha MK, Vandoni S (2019) Studying The Effects of supplementing ( Reashure ) to pregnant sheep on incidence of ketosis Health status Pre and after lambing. J Anim Sci livest Prod 3: 20

\section{Citation:}

Osman A Hameed (2021) Review on Pregnancy Toxemia in Sheep with Observation of Resolution Using ReaShure (Protected Choline). Integr J Vet Biosci Volume 5(2): $1-2$. 